\title{
The study of the lining layer abrasing wear in the semi- autogenous grinding mill
}

\author{
Mykola Sokur ${ }^{1}$, Volodymyr Biletskyi ${ }^{2,}$, Mykhailo Fyk², Oleksandr Fyk ${ }^{3}$, and Igor Zaselskiy ${ }^{4}$ \\ ${ }^{1}$ Kremenchuk Mykhailo Ostrohradskyi National University, Marketing Department, 20 Pershotravneva Str., Kremenchuk, 39614 , \\ Ukraine \\ ${ }^{2}$ National Technical University “Kharkiv Polytechnic Institute”, Department of Oil, Gas and Condensate Extraction, 2 Kyrpychova Str., \\ Kharkiv, 61002, Ukraine \\ ${ }^{3}$ National Academy of the National Guard of Ukraine, Department of Informatics and Applied Information Technologies, 3 Zakhysnykiv \\ Ukrainy Sq., Kharkiv, 61001, Ukraine \\ ${ }^{4}$ Kryvyi Rih Metallurgical Institute of the National Metallurgical Academy of Ukraine, 5 Stephana Tilhy Str., Kryvyi Rih, 50006, \\ Ukraine
}

\begin{abstract}
In this work complex investigations of the abrasing wear of lining of self-grinding mills (semiautogenous grinding mills) are carried out with the obtaining of mathematical models of wear-abrasing of elevators in terms of height, weight, volume and worn-out area. In particular, according to the location and nature of the abrasing wear processes, the liner-lifters mill self-grinding are identified in three typical groups. During 1 year, in the conditions of Ingulets GOK, the monitoring of the abrasing wear of selected groups of lifters of self-grinding mills was performed. On the basis of the experimental data calculationed in the Microsoft Office Excel program, a set of mathematical models of lifter abrasing wear was obtained in terms of height, weight, volume and worn-out area. The obtained dependencies are recommended for prediction of abrasing wear of lining and necessary frequency of replacement of inserts-lifters. In addition, the research of wear of lining made of cast iron RF-4, showed a significant reduction in their abrasing wear compared with steel 110G13L. Thus, it has been shown that the selection of liner-lifters materials can reduce the inter-repair period by 3 times or more (replacement of worn-out lifters). A comparison of the actual picture of the abrasing wear of elevators and Simulation Statics simulated result (using SolidWorks) stresses shows the convergence of the arrangement of the zones of maximum stresses and the maximum abrasing wear of the lining. Investigation of the influence of the stressed state of lining plates on the intensity of their abrasing wear - a promising direction for further research.
\end{abstract}

\section{Introduction}

The process of destruction (grinding and crushing) of mineral raw materials is the most energy-intensive and labor-intensive technological operation of ore dressing [1-3]. Investigation of the energy intensity of the processes of ore preparation, including the disintegration of ore, which was carried out in Eastern Europe in 14 mining ore dressing plants that process different raw material physical and mechanical properties, show that $50-70 \%$ of the total ore disintegration process accounts for $50-70 \%$ expenses, while the electric power consumption for grinding is on average about $60 \%$, and for crushing only 5\% [4-6]. It actualizes the research of equipment and technology of milling minerals.

From the end of the twentieth century semiautogenous grinding (SAG) of ores is the most progressive technology of ore preparation in world practice. As of 2010, in the world mining industry, about 200 large mills of full or partial SAG were in operation, including about 100 of them working in the iron ore industry, 30 in copper, while others - in dressing ore of rare and noble metals. In comparison with grinding in rod and ball mills SAG is characterized by a number of advantages:

- stages of middle and small grinding are excluded;

- saving of crushing bodies (balls and rods are not used);

- there is no contamination of the crushed material with metal;

- improvement of technological indicators of further dressing due to better disclosure and less sludge formation;

- in the processing of gold-bearing ores followed by cyanide losses of gold with iron scrap and crumbs are eliminated, the consumption of cyanide is reduced and the working conditions on quartz and silicone-sensitive ores are improved;

- when flotation of molybdenum ores, the use of SAG (self-grinding) mills improves the dressing rates associated with less "molten" scaling of molybdenite $[1$, $5-8]$.

* Corresponding author: ukcdb@i.ua 
The critical nodes of semi-self-grinding mills from a techno-economic point of view are drum lining, bearings, washing drum, gear gears of power drives (Figure 1), which account for $70-90 \%$ of operating costs [5].

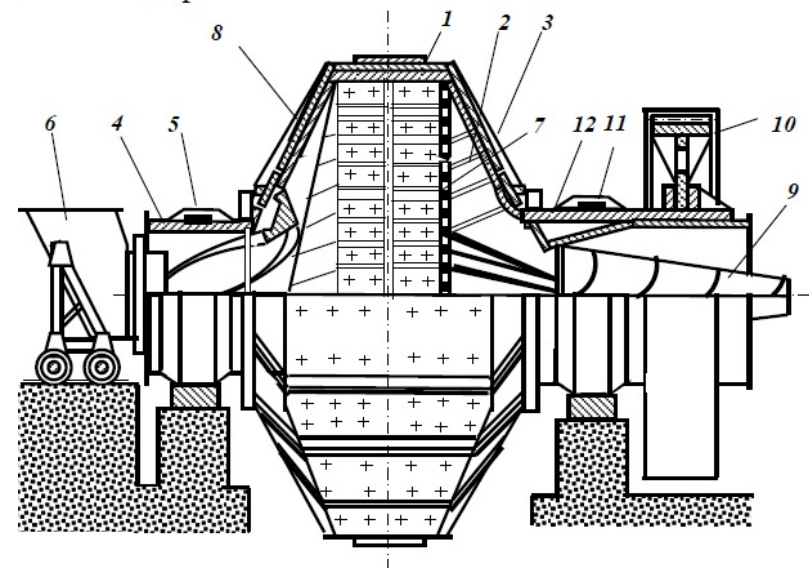

Fig. 1. The mill is a wet type of self-grinding type "Cascade", a general view: 1 -drum; 2 - lifts; 3, 8 - face caps; 4 - boot pin; 5, 11 - bearings; 6 - boot device; 7 - grating; 9 - washing drum; 10 - crown gear; 12 - unloading pin.

Of these, more than $50 \%$ - the proportion of lining (its cost, the cost of installation work, planned idle time). Therefore, durability and reliability of lining is a topical scientific and technical problem.

The process of abrasing the lining is determined by the energy of mechanical influence on it from the ore, the strong characteristics of the lining itself and miling ore. Proceeding from this, the following factors significantly affect the abrasing wear of the lining:

- the size of the lumps of the original material;

- maximum mass of ore lumps;

- durability and wear resistance of lining material;

- height of fall of ore lumps (pieces);

- sliding of the rock mass on the lining, which is determined by its profile;

- degree of filling of the drum mill and its frequency of rotation;

- properties of ore: strength, abrasiveness, and in the case of wet grinding - also the density of the pulp.

The lifts in the mills play two important functions first, it is protection against the wear of the mill shell. Secondly, it is ensured that the ore is raised, when they rotate the drum, they capture pieces of ore, lift them to a certain height, falling from which the ore is self-milling. Therefore, the efficiency of the process of SAG ore in the mills depends to a large extent on the design, location and serviceability of lifters.

\section{Literature review}

Many researchers have investigated the processes of abrasing wear of the lining of the semi-autogenous grinding mills and the impact of wear-abrasing on the technical parameters of the milling process. In work [9] the effect of lining liners wear on the productivity of the mill was studied. An analysis of fully worn and new inserts-lifters was conducted, as it was in line with the major changes in the mill's operating conditions. It has been found that worn-out mills are more prone to obtaining fine classes, possibly due to the reduction of strong collisions with high impact energy. When abrasing lining material is ground mainly in cascade mode, and with the new lining - in the waterfall mode. Consequently, the wear of inserts-lifts affects the mill operation. Cascade mode (worn out elevators) causes an increased throughput of the mill at lower power.

In [10], the demolition of liners made from martensitic $\mathrm{Cr}-\mathrm{Mo}$ steel was investigated. It has been shown that the replacement the WS-7HM (400 Brinell hardness) material on WS-222 (Brinell 500) material resulted in a $61 \%$ lengthening lifespan lifespan, a $38 \%$ reduction in the consumption of liner and a $7 \%$ overall material. In addition, the heterogeneity of the wear of the liners was discovered and their rational form was proposed, which takes into account the location in the working space of the mill.

In the paper [11], based on experimental studies and long-term observations, a quantitative assessment of the impact of wear on the liner-lifters on the milling performance itself was made. At the investigated mill there was an increase in the throughput of $10.5 \%$ over the life of the elevator. Separate effects of wear of the lift have also been isolated. It is established that increasing the throughput due to the wear of the liner can be further divided into the following components:

- an increase in the lattice diaphragm, 5.3\%;

- an increase in the diameter of the mill, $3.2 \%$, and

- a change in the profile of the insert, $2.0 \%$.

D. Royston summing up the experience of Royston Process Technology Pty Ltd. and others. indicates that, taking into account studies of lifts of mills, self-milling for deterioration for their manufacture, the following main materials are used: heat-treated chromium-molybdenum (Cr-Mo) alloyed steel (hardness about 350 Brinell), bimetallic inserts using an "white iron" insert that can provide increased wear and tear in places prone to abrasion (end lining). In addition, polymeric rubber products that provide structural stability can be used as inserts [12].

In work [13] a modification of the form of an insertlifter SAG was performed based on the 3D measurement of the wear profile of the insert. Experimentally, with the help of a specially designed measuring device it was established that the wear profile is not homogeneous. When finding the appropriate models that accurately described the wear rate of the liners, in order to achieve an even profile of the liner when removing the elevator, new designs of the liners were proposed. This not only increased the lifetime of the elevator, but also reduced the content of scrap metal. Application of the proposed method in the SAG mill $9.75 \times 4.88 \mathrm{~m}$ showed that the wear profile of the insert along its length was uneven and the highest wear was between $1.25 \mathrm{~m}$ and $2.75 \mathrm{~m}$ in length of the shell of the mill. The proposed liners, unlike the standard type, did not have a uniform shape, and the height of the liners increased from $152 \mathrm{~mm}$ to $187 \mathrm{~mm}$ in the area where the wear rate was high. It is established that this new profile comes to a uniform profile at the time of insertion change. Such a technical decision has reduced 
the amount of scrap to $30 \%$ of the current value of $47 \%$, and on average lifetime of the liner will increase by $1500 \mathrm{~h}$.

A similar approach to the retention of rational form of lining is also used in work [14]. Forecasting the evolution of the shape of the liner and changing performance during the lifecycle lifter allowed to offer a rational form of lifters. Forecasting of the dynamics of wear of elevator is done by the method of discrete elements (DEM). An analysis of the life cycle of the insert has shown a $20 \%$ reduction in power consumption, since increasing the volume of the SAG working chamber and blurring the profile of the lifts leads to less efficient mill operation.

At the same time, now is a lack of real comprehensive research on the wear of lining of SAG mills with the simulation of wear and abrasing of elevators in terms of height, weight, volume and worn-out area.

\section{Research objective and tasks}

The purpose of this article is a comprehensive research on the wear-abrasing of lining mills of the same milling with the obtaining of mathematical models of wear-abrasing of elevators in height, weight, volume and worn out area. To achieve this goal, the following research objectives are formulated:

- in the actual conditions of the Ingulets GOK to monitor the wear-abrasing of lifters of mills for self-grinding. According to the results of the monitoring, identify the typical groups of lifts-lifters;

- on the basis of the experimental data calculation in the Microsoft Office Excel, to obtain a set of mathematical models of lining of the elevators in terms of height, weight, volume and worn-out area;

- to analyze the wear of lifters made of steel 110G13L and cast iron RF-4;

- using the SolidWorks software simulation statics module to investigate the mechanical stresses in the work area of the lifters and compare the data with the actual picture of data of their wear.

\section{Basic stages and research results}

In the conditions of the preparation plant Ingulets GOK preparation plant (Kryvyi Rih iron ore basin, Ukraine), the nature and patterns of abrasing wear of MMS-70-23 mills were investigated. In this case, elevators made of $110 \mathrm{G} 13 \mathrm{~L}$ steel, by location, were divided into three groups (Figure 2):

I. Lifts No. 2 and 3, located on the end wall of the loading;

II Lifts No. 5, located on the shell;

III Lifts No. 7 and 8, located on the end wall of the unloading.

In addition, on a pilot sample mill MMS-90-30 the durability of lifters from cast iron $\mathrm{RF}-4$ and SS alloy was investigated.

In researches in work the experimental researches of wearing of lining of mills of self-grinding in industrial conditions of mining complexes of Kryvyi Rih basin which generally lasted for more than 1 year were used.
The experimental data processing is done in the Microsoft Office Excel resource with the obtaining of mathematical models of polynomials and abrasing wear curves of elevators in height, mass and volume abrasing wear of elevators from the amount of processed ore and depending on the duration of their operation.
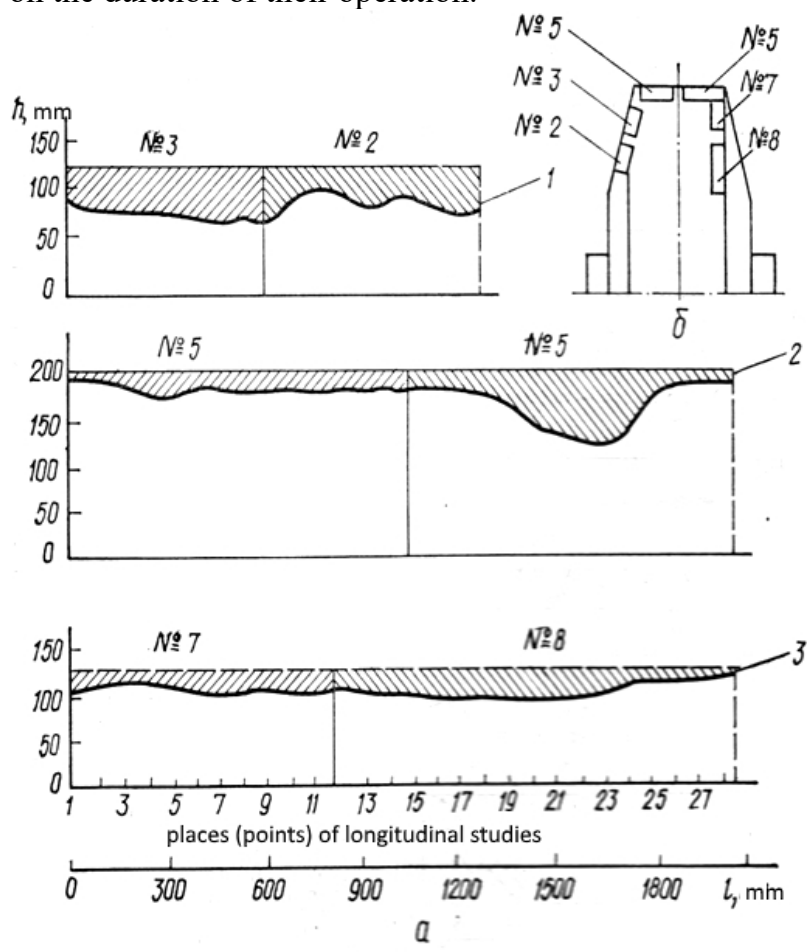

Fig. 2. Wear of lifters of mills MMS-70-23 at height $h$ of a working surface $(a)$ and a scheme of their location in a drum $(\delta) . l$ - the metric size of elevators.

\subsection{The first stage of research}

The wear of lifters was measured at intervals of $1-1,5$ months. The height of their working part and (h, mm) and volume $\left(\mathrm{V}, \mathrm{cm}^{3}\right)$ was measured. In this case, the period of work of lifters and the volume of processed miner's mass were recorded. Elevators were measured at several points (Figure 2). The last measurement was carried out after processing 200 thousand tons of ore.

Let's analyze the results. As you can see from Fig. $2 a$, lifters number 2 and 3 wear out basically evenly. The maximum wear is observed at the junction - here the height of their working part decreases from 125 to $75 \mathrm{~mm}$.

Lifts No. 5 wear out very unevenly. The greatest deterioration is observed on the elevators located on the side of the discharge - here they wear about half their height. The fact is that in the drum mill near the discharge grid there is an increased circulation of crushed rock mass, which also causes the heavy wear of these elevators before the unloading lattice.

The wear of lifters number 7 and 8 is uniform throughout their length, maximum wear in height -30 $35 \mathrm{~mm}$.

\subsection{The second stage of research}

For an in-depth study of the wear of elevators of selected 
groups I-III, their height was determined depending on the amount of processed mass. According to experimental data analize in the Microsoft Office Excel, curves of wear and tear of elevators and mathematical polynomial models are obtained in height from the amount of processed ore of Figure 3.

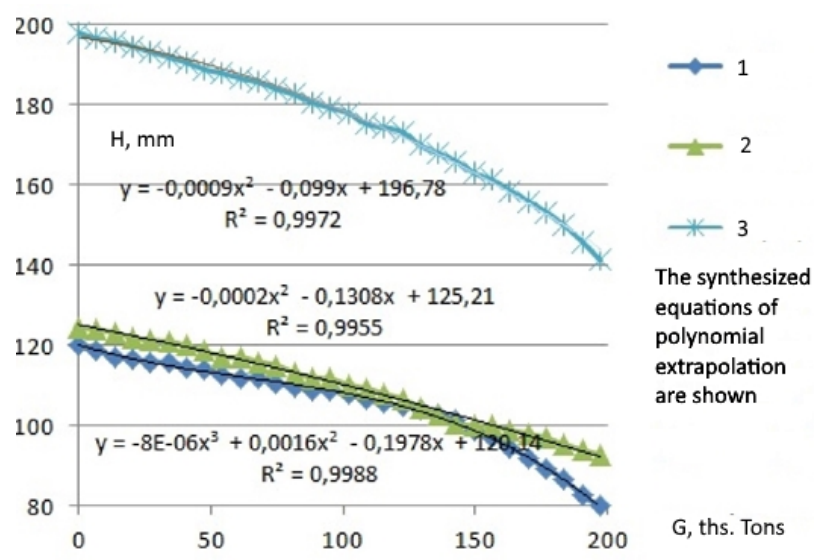

Fig. 3. Dependence of lifters wear in height $\mathrm{H}(\mathrm{mm})$ on the amount of processed ore $\mathrm{G}$ (ths. tons). 1 - lifts No. 1 and 3; 2 lifts No. $5 ; 3-$ lifts No. 7 and 8 .

The analysis of the obtained data shows that lifters No. 1 and 3 on the part of loading and No.7 and 8 on the part of unloading in height wear out with the same intensity before the processing of the first 120 thousand tons of ore. After that, the intensity of wear of lifters number 1 and 3 increases and after processing 200 thousand tons of ore their average height is almost $20 \mathrm{~mm}$ less than the height of lifters number 7 and 8 . This, obviously, can be explained by the result of the action on the lifters by loading more large and abrasive lumps of ore than by unloading.

As measurements show, lifters number 5 wear out more intensively and after processing 200 thousand tons of ore, the average height of their working part decreases from 195 to $140 \mathrm{~mm}$.

\subsection{Third stage of research}

Investigated the massive and volumetric wear of elevators. The results are shown in Figure 4 - dependence of mass and volume wear of lifters on the amount of ore processed $\mathrm{G}$, ths. tons (and corresponding polynomial mathematical models).

The analysis of the obtained model curves shows that lifts number 5, 7 and 8 throughout the life of the service are worn evenly and after processing 200 thousand tons of ore their wear reaches 140 and $120 \mathrm{~kg}$, respectively.

Lifts No. 1, 2, and 3 are worn less intensively before the processing of 100 thousand tons of ore, after which the intensity of their wear increases sharply and reaches $105 \mathrm{~kg}$ by the end of its lifetime.

\subsection{Fourth research phase}

The dynamics of the expansion of the conditioned wearing lining area $S_{\mathrm{sn}}$ was investigated, depending on the amount of ore processed $\mathrm{G}$, ths. tons.

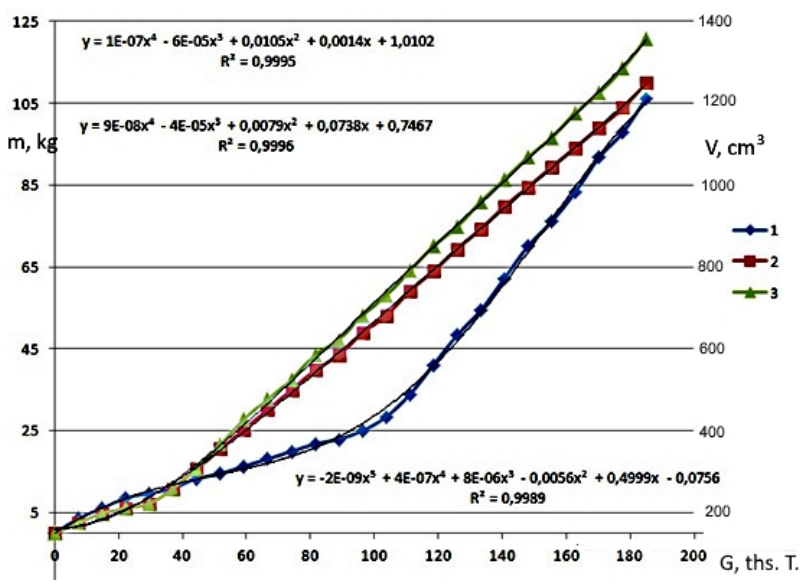

Fig. 4. Dependence of mass $(\mathrm{kg})$ and volumetric $\left(\mathrm{cm}^{3}\right)$ wear of lifters on the amount of processed ore G, ths. tons. 1 - lifts No. 1 and $3 ; 2-$ lifts No. 5; 3 - lifts No. 7 and 8.

For this purpose, the amount of wear was divided into a height of wear for a particular elevator. For example, for elevator No.5 $\left(S_{s n 5}\right)$ using the corresponding polynominal models we find:

$$
S_{\text {sn } 5}=\frac{-0,0001 x^{3}+0,0506 x^{2}+2,8976 x-5,4119}{-0,0009 x^{2}-0.099 x+196.78}
$$

After calculations, we obtain the dependence $S_{s n 5}$ $\left(\mathrm{cm}^{2}\right)$ given in Figure 5.

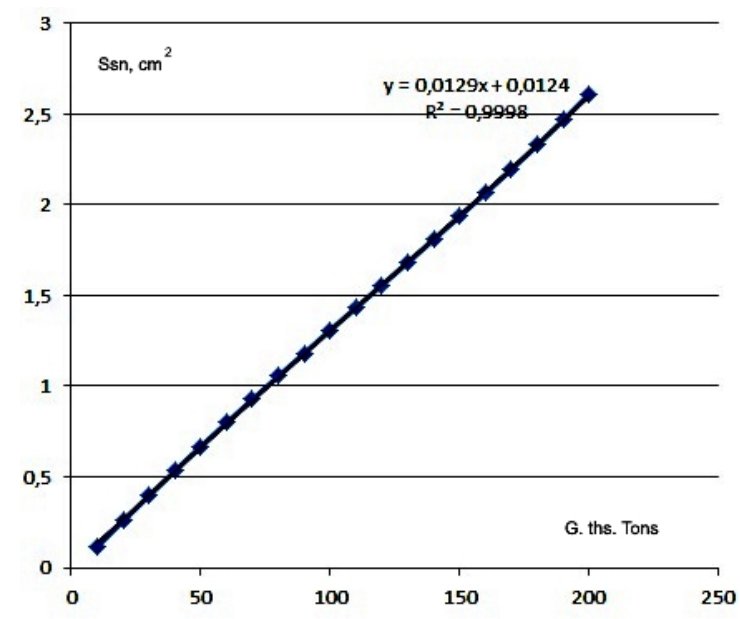

Fig. 5. Growth of the conditional worn-out area $\mathrm{S}_{\mathrm{sn}}\left(\mathrm{cm}^{2}\right)$, lining depending on the amount of ore processed G, ths. tons.

As you can see, the expansion of the conditional wornout area of the $S_{s n}$ lining is linear and directly proportional to the volume of crushed ore.

\subsection{Fifth stage of research}

On a pilot sample mill MMS-90-30 also conducted researches of wear of elements of lining, made of cast iron RF-4. To characterize the wear of the lining, mass deterioration of all its elements was determined (Table 1).

From the analysis of the data obtained, it can be seen that the lifters made of cast iron $\mathrm{RF}-4$, for 5 months of 
work, were worn only $15 \mathrm{~mm}$ and were suitable for further operation. During this time, serial lifters from the $110 \mathrm{G} 13 \mathrm{~L}$ alloy were worn by an average of $55 \mathrm{~mm}$ in height and were partially replaced by new ones. From the SS alloy were manufactured and tested lifts 2 and 3 . Lifts 3 for wear resistance were the same as serial lifts from steel $110 \mathrm{G} 13 \mathrm{~L}$. The durability of lifters 2 from the SS alloy was significantly higher: after 5 months of operation, their average height was $110 \mathrm{~mm}$, while the height of serial lifters decreased to $80 \mathrm{~mm}$.

Table 1. Results of research of wear of lining of mill MMS-90-30.

\begin{tabular}{|l|c|c|c|c|c|c|}
\hline Lining & $\begin{array}{c}\text { Num- } \\
\text { ber }\end{array}$ & $\begin{array}{c}\text { Total } \\
\text { mass, } \\
\text { kg }\end{array}$ & $\begin{array}{c}\text { Mass of } \\
\text { worn } \\
\text { part, } \\
\text { kg }\end{array}$ & $\begin{array}{c}\text { Relati- } \\
\text { ve we- } \\
\text { ar, } \\
\text { mass, } \\
\text { \%o }\end{array}$ & $\begin{array}{c}\text { Pro- } \\
\text { cessing } \\
\text { of ore, } \\
\text { tons }\end{array}$ & $\begin{array}{c}\text { Specific } \\
\text { costs of } \\
\text { mass li- } \\
\text { ning, kg }\end{array}$ \\
\hline $\begin{array}{l}\text { Lining } \\
\text { of the } \\
\text { loading } \\
\text { end wall }\end{array}$ & 98 & 37159 & 3255 & 8,76 & 379,3 & 8,587 \\
\hline
\end{tabular}

\begin{tabular}{|l|c|c|c|c|c|c|}
\hline Lining & $\begin{array}{c}\text { Num- } \\
\text { ber }\end{array}$ & $\begin{array}{c}\text { Total } \\
\text { mass, } \\
\text { kg }\end{array}$ & $\begin{array}{c}\text { Mass of } \\
\text { worn } \\
\text { part, } \\
\text { kg }\end{array}$ & $\begin{array}{c}\text { Relati- } \\
\text { ve we- } \\
\text { ar, } \\
\text { mass, } \\
\text { \% }\end{array}$ & $\begin{array}{c}\text { Pro- } \\
\text { cessing } \\
\text { of ore, } \\
\text { tons }\end{array}$ & $\begin{array}{c}\text { Specific } \\
\text { costs of } \\
\text { mass li- } \\
\text { ning, kg }\end{array}$ \\
\hline $\begin{array}{l}\text { Load } \\
\text { lifts }\end{array}$ & 84 & 14504 & 3460 & 23,85 & 379,3 & 9,122 \\
\hline $\begin{array}{l}\text { Armor } \\
\text { shell } \\
\text { ring }\end{array}$ & 56 & 38080 & 1120 & 2,94 & 379,3 & 2,953 \\
\hline $\begin{array}{l}\text { Lifts } \\
\text { collars }\end{array}$ & 56 & 22960 & 4200 & 18,29 & 379,3 & 11,073 \\
\hline $\begin{array}{l}\text { Grates } \\
\text { Lattice } \\
\text { moun- } \\
\text { ting lifts }\end{array}$ & 70 & 23157 & 7486 & 32,27 & 379,3 & 19,736 \\
\hline $\begin{array}{l}\text { Lining } \\
\text { under } \\
\text { grates }\end{array}$ & 70 & 63084 & 9364 & 14,84 & 379,3 & 24,687 \\
\hline $\begin{array}{l}\text { Com- } \\
\text { plete li- } \\
\text { ning kit }\end{array}$ & 504 & 214526 & 29955 & 13,96 & 379,3 & 78,978 \\
\hline
\end{tabular}

Model Name: Part No. 1.

Study Name: Statistical Analysis No. 1

Type of plot: Statistical analysis of nodal stress.

Mechanical stress No. 1
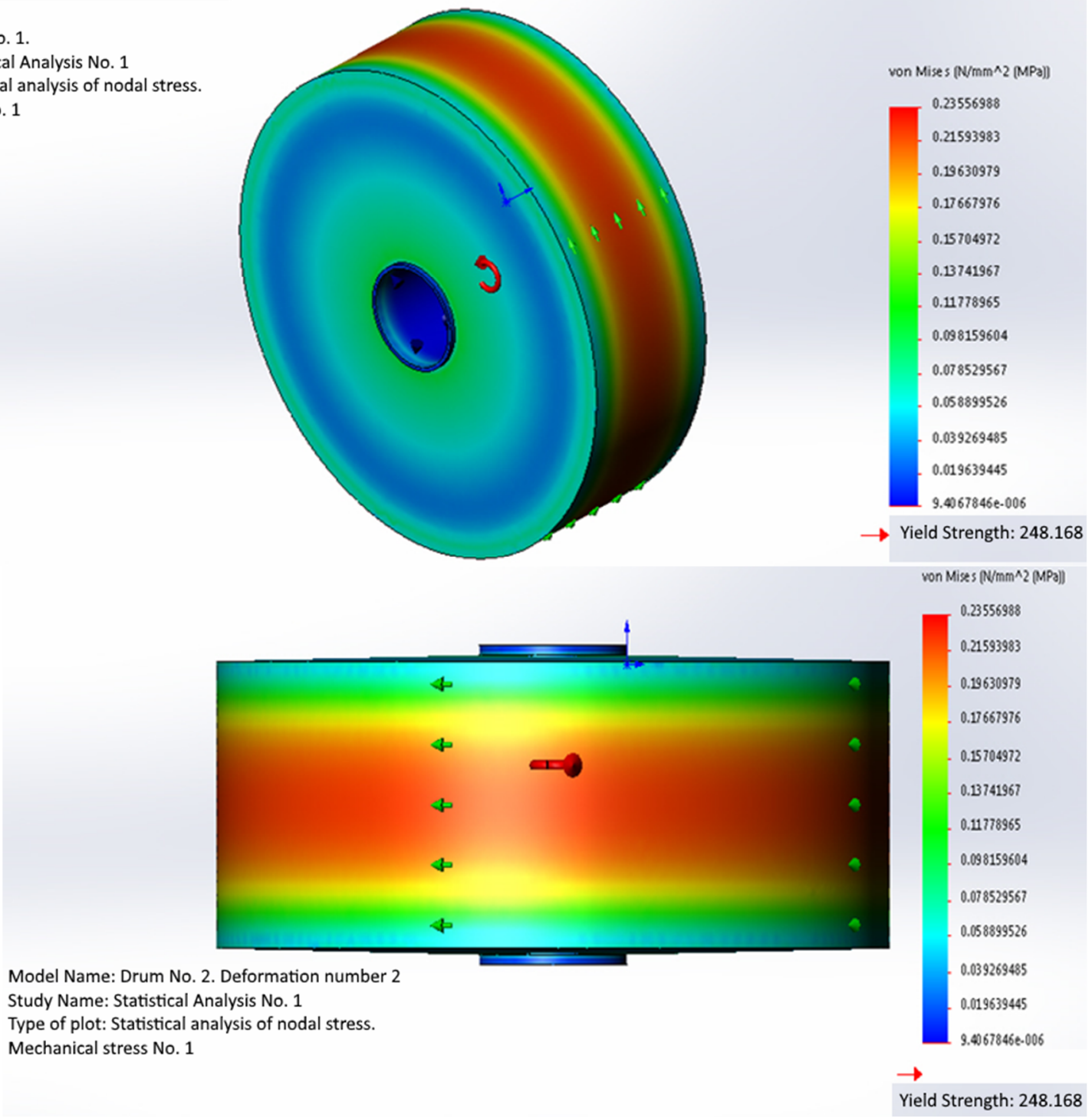

Fig. 6. Parametric field of strength of the drum mill self-grinding at idling speed. Trapezoidal drum wall with bases: upper - $70 \mathrm{~mm}$, bottom $-200 \mathrm{~mm}$ : a - isometric projection of the drum; b-the drum's side (profile). 
The nature of the wear of elevator lifters in height is the same as the elevators of the mill MMS-70-23.

Experience has shown that lining, made of wearresistant cast iron $\mathrm{RF}-4$, is more durable than lining steel 110G13L. Lifts, made of cast iron RF-4, especially lift loaders, are more fragile and after 3-4 months. Operation is broken up by large pieces of ore, which is fed into a mill. Broken and torn elevators during rotation of the drum break other elements of the lining, which leads to the need for premature stopping of the mill for re-fusion. The following lines of service of separate groups of lining of mills MMS-90-30 are established: the armor of the loading end wall - 5-7 months; load lifters - up to 5; armor and lifts of luggage - up to 4; lattices - up to 4; sublattice lining $-7-8$ months. Thus, the service life of individual elements of the lining of mills MMC-90-30 is relatively low and, most importantly, is unplanned, which makes it difficult to establish optimal inter-repair periods. In addition, the lack of service life of individual elements of the lining leads to the fact that when replacing a number of extremely worn items must be replaced and those elements whose wear is insignificant and they could work for a long period.

A significant disadvantage of the lining of mills MMC-90-30, which negatively affects the term of their service, there is also low reliability of nodes fixing elevators and lattices. As a result, there were cases of a breakdown of relatively few worn elevators and the loss of grate, which as a result of the dynamic impact in the process of the mill on other elements of lining removed them from the system. Therefore, in order to increase the efficiency, wear resistance and durability of the lining of serial mills MMS-90-30, it is necessary to apply highstrength materials and constructive improvement of all elements of lining, especially the nodes of fastening of elevators and lattices.

\subsection{The sixth phase of the research}

At this stage, using the SolidWorks software simulation statics module, mechanical stresses in the area of the shell were investigated. The obtained models in the idle mode mill mill itself (Figure 6) show an abnormally high mechanical tension in the vicinity of the vertical axis of the drum. For the loaded (nominal) operating mode of the mill itself, the grinding by the rule of superposition should be expected to increase the voltage in this zone - as the voltage at idle and the load factor will be added.

Reception of the epic of the stress of the elements of the drum mill self-crushing at different loads of the mill in the ore is an independent task and is planned by us in the subsequent studies.

At the same time, it should be emphasized the convergence of the data of simulation of mechanical stresses in the zone of the shell (Figure 6) and the real one, - experimentally established, - pictures of wear of the lining of mill MMS-90-30A (Figure 7).

\section{Conclusions}

1. According to the location and nature of the wear processes, inserts-lifts appropriate to be divided into the following groups: I. Lifts, located on the end wall of the load; II Lifts, located on the shell; III Lifts, located on the end wall on the side of unloading. Monitoring of wear of lifters of semi-autogenous grinding mills was executed in conditions of Ingulets GOK within 1 year.

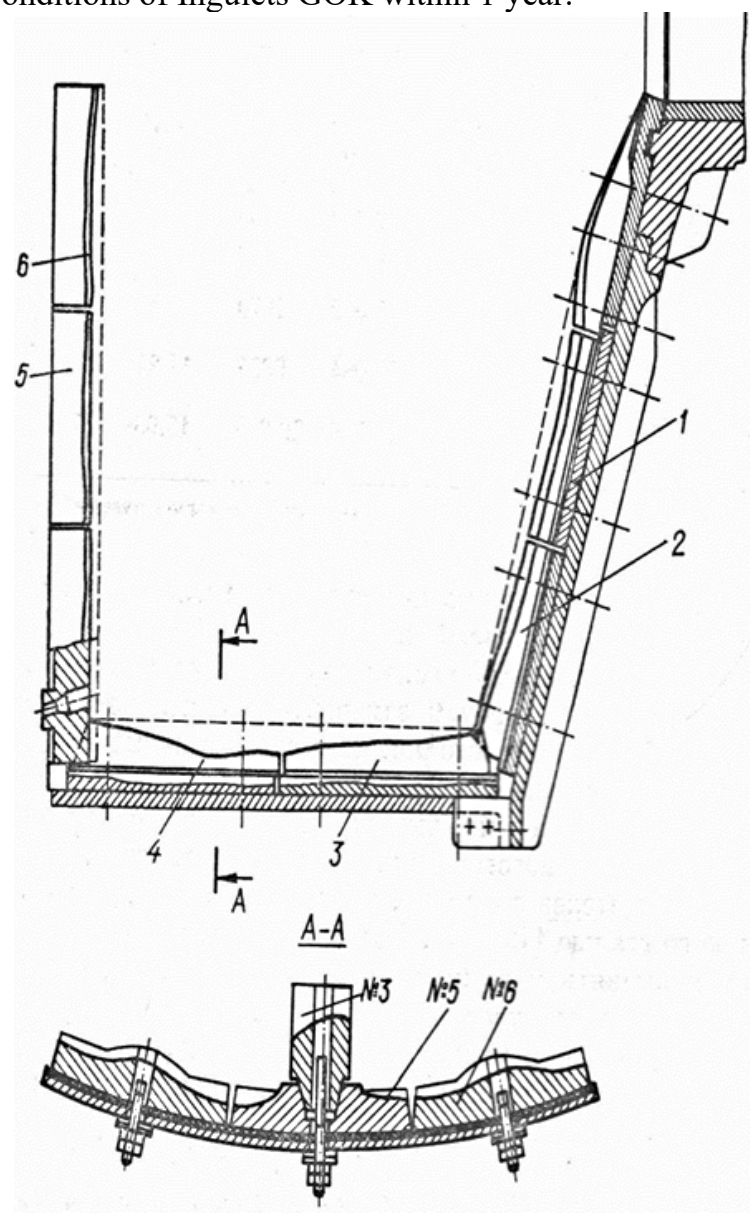

Fig. 7. The demolition of elements of lining of mills MMS-90$30 \mathrm{~A}$ was experimentally established. 1,2 - lining and lifters of the loading end wall; 3, 4 - lining and lifts of the drum shell; 5, 6 - gratings and lifters of the zone of unloading; No. 3, 5, 6the numbers of lining and lifts of the lining.

2. On the basis of the experimental data regression received in the Microsoft Office Excel, a set of mathematical models of lifters' wear was obtained in terms of height, weight, volume and worn-out area.

3 . From the analysis of the obtained data it is seen that the lifters made of cast iron RF-4, for 5 months of work, were worn only $15 \mathrm{~mm}$ and were suitable for further operation; During this time, serial lifters from the 110G13L alloy were worn by an average of $55 \mathrm{~mm}$ in height and were partially replaced by new ones. Thus, the selection of lift materials can be reduced by 3 times the inter-repair period (replacement of worn lifts).

4. Comparison of the real picture of wear of elevators and simulated using the simulation statics module SolidWorks stresses shows the convergence of the arrangement of zones of maximum stresses and maximum wear of the lining.

The authors thank the management of the Ingulets GOK's ore dressing plant, the Mekhanobrchormet Research Institute for its assistance in conducting research. 


\section{References}

1. M.I. Sokur, M.V. Kiianovskyi, O.M. Vorobiov et al., Dezintehratsiia mineralnykh resursiv (Disintegration of mineral resources). (Vydavnytstvo PP Shcherbatykh O.V., Kremenchuk, 2014)

2. R. Pothina, V. Kecojevic, M.S. Klima, D. Komljenovic, Gyratory crusher model and impact parameters related to energy consumption. Mining, Metallurgy \& Exploration 24, 170-180 (2007). doi:10.1007/BF03403212

3. J.G. Donovan, Fracture Toughness Based Models for the Prediction of Power Consumption, Product Size, and Capacity of Jaw Crushers, Dissertation, Virginia Polytechnic Institute and State University, 2003

4. M. Silva, A. Casali, Modelling SAG milling power and specific energy consumption including the feed percentage of intermediate size particles. Minerals Engineering 70, 156-161 (2015). doi:10.1016/j.mineng.2014.09.013

5. M.I. Sokur, V.S. Biletskyi, O.I. Yehurnov, O.M. Vorobiov, V.O. Smyrnov, D.P. Bozhyk, Pidhotovka korysnykh kopalyn do zbahachennia (Preparation of minerals for enrichment). (PP Shcherbatykh O.V., Kremenchuk, 2017)

6. N. Sokur, V. Biletskyy, L. Sokur, D. Bozyk, I. Sokur, Investigation of the process of crushing solid materials in the centrifugal disintegrators. EasternEuropean Journal of Enterprise Technologies 3(7(81)), 34-40 (2016). doi:10.15587/17294061.2016 .71983

7. G.G. Stanley, Mechanisms in the autogenous mill and their mathematical representation. Journal of the South African Institute of Mining and Metallurgy 75, 77-98 (1974),

https://www.saimm.co.za/Journal/v075n04p077.pdf. Accessed 21 Mar 2020

8. S. Morrell, A new autogenous and semi-autogenous mill model for scale-up, design and optimization. Minerals Engineering 17(3), 437-445 (2004). doi:10.1016/j.mineng.2003.10.013

9. P. Toor, M.S. Powell, M. Hilden, N.S. Weerasekara, Understanding the effects of liner wear on SAG mill performance, in MetPlant-2015, Perth, Australia.

10. W.C. Dailey, Wet Semi-autogenous Grinding Mills, in SME-AIME Fall Meeting, Albuquerque, New Mexico. October 16-18, 1985. Society of mining engineers. Preprint No. 85-405, https://www.911 metallurgist.com/wet-semiautogenous-grinding-mills/. Accessed 10 Apr 2020

11. P. Toor, Quantifying the Influence of Liner Wear on SAG Mill Performance, MPhil Thesis, Sustainable Minerals Institute, The University of Queensland, 2013. doi:10.14264/uq1.2014.112

12. D. Royston, Semi-autogenous grinding (SAG) mill liner design and development. Mining, Metallurgy \& Exploration 24 , doi:10.1007/BF03403206
13. M. Yahyaei, S. Banisi, M. Hadizadeh, Modification of SAG mill liner shape based on 3-D liner wear profile measurements. International Journal of Mineral Processing 91(3-4), 111-115 (2009). doi:10.1016/j.minpro.2009.02.002

14. P.W. Cleary, P.Owen, D.I. Hoyer, S. Marshall, Prediction of mill liner shape evolution and changing operational performance during the liner life cycle: Case study of a Hicom mill. International Journal for Numerical Methods 81(9), 1157-1179 (2010). doi:10.1002/nme.2721 